\title{
Bridging The CPA Exam Gap: Do Internships Matter?
}

\author{
Stephanie Hairston, Georgia Southern University, USA \\ Charles Harter, Georgia Southern University, USA \\ Britton McKay, Georgia Southern University, USA
}

\begin{abstract}
In this paper we consider whether experience gained on the job through an internship results in knowledge that can help with passing the CPA exam. It would seem that a candidate for the CPA exam would be better prepared if they had the combination of education and practical experience. We examine the CPA exam performance of 72 graduate students that completed a public accounting internship prior to sitting for the CPA exam compared to 98 graduate students that did not complete an internship in public accounting. Our analysis indicates that on average students completing internships score higher on all parts of the CPA exam. In addition, on average, students completing internships had a higher overall pass rate for each section of the exam, with the pass rate for the Regulation (REG) section being significantly higher for students that have completed internships; we also find that on average students with internships pass 2 sections of the exam prior to graduation as compared to 1.69 for students that have not completed internships.
\end{abstract}

Keywords: CPA Exam; CPA Exam Pass Rate; Internship

\section{INTRODUCTION}

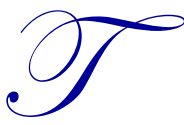

he CPA exam gap refers to the difference between those who graduated with accounting degrees and those that go on to sit for and pass the CPA Exam. According to the AICPA 2017 Trends Report, this "gap" is shrinking with the number of CPA exam candidates sitting for and passing all four sections increasing seven percent between 2015 and 2016; however, it may not be fast enough as 88 percent of U.S. CPA firms intend to hire more CPAs.

Most would agree that experience is important to the success of a CPA. In fact, all jurisdictions require some experience to obtain a license to practice as a CPA. The experience requirement has been studied by the AICPA and the American Accounting Association (AAA). In a Journal of Accountancy article, Bruschi states that "personal participation in activities results in the accumulation of knowledge and the development of skills and judgement that cannot be readily obtained in any other way. People learn by doing (Bruschi, 1969)." In this paper we consider whether experience gained on the job through an internship results in knowledge that can help with passing the CPA exam. It would seem that a candidate for the CPA exam would be better prepared if they had the combination of education and practical experience. Our analysis indicates that on average students completing internships score higher on all parts of the CPA exam.

\section{IMPORTANCE OF THE CPA EXAM}

The CPA exam was first introduced in June of 1917 when the Institute of Public Accountants (IPA) offered to develop and grade an exam that would provide a uniform assessment of newly licensed CPAs entering the profession. The state boards of Kansas, New Hampshire, and Oregon accepted the offer (Decker, 2017). Requirements for membership in the IPA included five years of practical experience and passage of the professional exam. The IPA's name was changed in 1957 to its current name of American Institute of Certified Public Accountants (AICPA). Over the years the exam and the experience requirements have changed as the profession has evolved. Until the end of 2003 the exam was pencil and paper. As a reflection of the importance of technology in the profession, in 2004 the exam was moved 
to a computer based format. In April of 2017 the exam was changed again. Questions were modified with the intention of testing higher order skills based on Bloom's taxonomy of Educational Objectives. In order to ensure that the exam resembles the professional tools and work environment of a CPA the exam has also recently incorporated the use of excel spreadsheets. Over time the overriding goal of the CPA exam has been to ensure that new CPAs entering the profession had the competence to be successful. The global economy and technology have impacted the work of a CPA. Those entering the profession must assess situations and apply professional judgement. New CPAs must be more than book-smart, they must be able to apply knowledge to the situations at hand.

Public accounting firms emphasize that passing the exam early should be a priority for new hires given that preparation becomes increasingly difficult as accountants progress in their careers, and many firms encourage new hires to be qualified to sit for the challenging exam on day one. The push for licensure is often fraught with incentives for new hires such as time-based pass bonuses, financial support, mentorship, and a supportive culture. However, taking the exam with no relevant professional experience may be a mistake, particularly on the more concept-based material.

The coursework at Universities helps prepare students for the CPA exam. However, due to the amount of material covered during a student's coursework most candidates choose to take a review course to help with passing the exam. Some schools partner with a CPA review provider to make it easier for students to incorporate the review into their plan of study. Students are also encouraged to complete an internship during their undergraduate and/or Master of Accounting (MAcc) programs. According to the blueprint provided by the AICPA, the CPA exam is intended to determine if a newly licensed CPA is prepared to enter the profession. This blueprint implies that students that gain experience during their work in a CPA firm should be more prepared for the CPA exam than a candidate with no experience. We expect internships to help students gain experience necessary to be successful in the profession and on the CPA exam. We investigate this by comparing the success on the CPA exam of students completing internships to those not completing internships. All students in the study completed the same CPA review course.

The latest version of the exam is designed to emphasize higher order skills. Presumably an exam based on these higher order skills should be more difficult to pass using only memorization of accounting concepts and rules. According to the AICPA, the adoption of questions that require higher order skills enables testing that more closely resembles the tasks a newly licensed CPA may encounter. Much of the information necessary to pass the CPA exam can be obtained during the study of accounting at Universities. However, as the profession has developed, judgement and decision making have become more commonplace. Some of the higher order skills necessary for a successful CPA are likely best developed through on the job experience. Recognizing the importance of this experience every state has some sort of experience requirement to become a licensed CPA. Considering the importance of experience, it is likely that CPA exam candidates that complete an internship will perform better on the CPA exam.

\section{INTERNSHIP EXPERIENCE AND THE CPA EXAM}

The professional experience that students gain during an internship and the expressed goals of the CPA examination are congruent. Accounting has a strong reliance on experiential based learning and mastery of material. Procedural and declarative knowledge is acquired through experience involving practice and feedback (Bonner \& Walker, 1994). This is the typical approach of an internship. As such, CPA candidates that have had an internship or work experience should be better prepared for the material that is tested. It is often difficult for students to understand the conceptual material in an audit class without engaging in a real-life audit. The experience of auditing financial statements allows students to apply their conceptual knowledge to real-life scenarios. During an audit internship, students are likely to review and identify accounting and audit issues, research accounting and audit issues, perform analytical audit procedures, and test internal controls. Similarly, tax internships improve the ability of students to apply critical thinking skills in preforming tax research and completing complex returns. Finally, tax and audit internships reinforce classroom learning through the repetition of activities such as preparation of tax returns and correcting entries. Given that most students prefer application- as opposed to concept-based learning, internship experience should be invaluable in preparing students to successfully complete the CPA exam.

To examine the validity of these assertions, the CPA exam performance of 72 graduate students that completed a public accounting internship prior to sitting for the CPA exam is compared to 98 graduate students that did not 
complete an internship in public accounting. The sample of graduate students included 81 female students and 89 male students. The average undergraduate GPA of students entering the graduate program at the University is 3.34 , and the average age of students in the MAcc program is 26 . Approximately 75 percent of students in the graduate program received their undergraduate degree/s in Accounting and/or Business Administration. All of the students described in this study were enrolled in a university facilitated Becker CPA Exam Review course prior to sitting for the exam. ${ }^{1}$ The required courses for the graduate program are consistent for all students. ${ }^{2}$

We acknowledge that this is a small sample for comparison and as we drill down to individual sections of the exam, the group becomes smaller. Because of the small size, many of our findings have practical significance, but limited statistical significance. We perform t-tests to compare the differences between groups examined in this study and note that any reference to significant differences between groups is related the t-tests performed. However, our interpretation of this information from a practical standpoint does not change.

\section{RESULTS}

Our analysis indicates that on average students completing internships score higher on all parts of the CPA exam, but the difference in scores are only statistically significant for the Business Environment and Concepts (BEC) section. In addition, on average, students completing internships had a higher overall pass rate for each section of the exam, with the pass rate for the Regulation (REG) section being significantly higher for students that have completed internships; we also find that on average students with internships pass 2 sections of the exam prior to graduation as compared to 1.69 for students that have not completed internships. The remainder of the article explores a variety of additional factors that may affect an intern's experience and CPA exam performance such as, the semester that students' intern, if students intern during their graduate or undergraduate programs, and student gender.

Figure 1. Internship Comparison - Average CPA Exam Score

—INTERNSHIP —NO INTERNSHIP

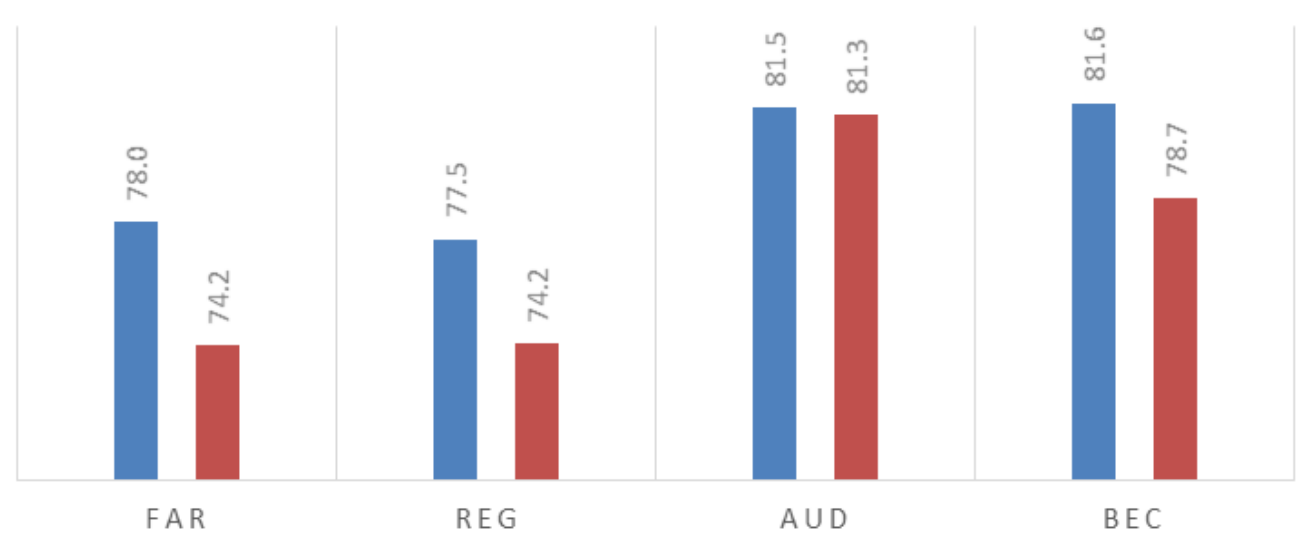

${ }^{1}$ Graduate students participating in the University's CPA review course are generally in the second semester of the MAcc program. Students in the
review course are required to take a 50 question multiple choice exam after each section of the Becker course (i. e. AUD, REG, FAR, and BEC).
Each time a student passes a section of the CPA exam the score portion of the class is changed to 100 percent instead of the score that they earned
on the 50 question exam. All students are on the same schedule so they all take the 50 question exam at the same time and should take the actual
CPA exam within 2 weeks of each exam. If students miss taking one or more of the class exams or don't pass the CPA exam they can and sometimes
do fail the course. However, this course does not deviate from the material covered in the Becker CPA review course and should be considered a
structured self-study course for students sitting the CPA exam.
${ }^{2}$ All students completing internships received course credit for their internship, a maximum of 3 credit hours. In order to be classified as a full-time
student, graduate students must be registered for at least 12 credit hours. Students in the CPA review course are also generally enrolled in at least
three other required courses. The internship program at the university is not completed concurrently with in-person course work; however, several
students have taken online courses while completing their internships. In order to receive course credit for an internship (as all students in this
article have) students must be full time employees at their firms. Copyright by author(s); $\underline{\mathrm{CC}-\mathrm{BY}}$ 


\section{Internship Semester}

Accounting internships can be completed during fall, spring or summer semesters, however, students participating in spring internships may have an edge on their summer counterparts. Spring is "busy season" for both tax and audit interns, which means that the students may participate in more projects and perform less rudimentary tasks than summer interns. Students may have a somewhat similar experience if they participate in an internship during the fall semester, as firms are preparing for busy season. However, summer tends to be slower pace for public accounting firms and by extension accounting interns. Firms tend to spend a significant amount of time finding work for interns as opposed to treating them as normal staff due to the lack of available work. As a result, spring interns may gain more knowledge during their internships, improving their CPA exam performance.

On average, the exam scores of students that completed spring or fall internships are higher than those that completed summer internships. Results are somewhat split regarding when the internship takes place. Students with spring internships obtain the highest scores on the Financial Accounting and Reporting (FAR) and Regulation (REG) sections as compared to students completing fall internships scoring highest on the Audit and Attestation (AUD) and Business and Economic Concepts (BEC) sections. The FAR scores of those students completing spring internships is also significantly higher than those completing internships during any other semester. Students that complete spring internships also score significantly higher on the BEC section of the test as compared to those that complete summer internships. When you consider that many spring internships have a tax component, the relationship between practice and knowledge acquisition is reinforced.

Figure 2. Average CPA Exam Scores by Internship Semester

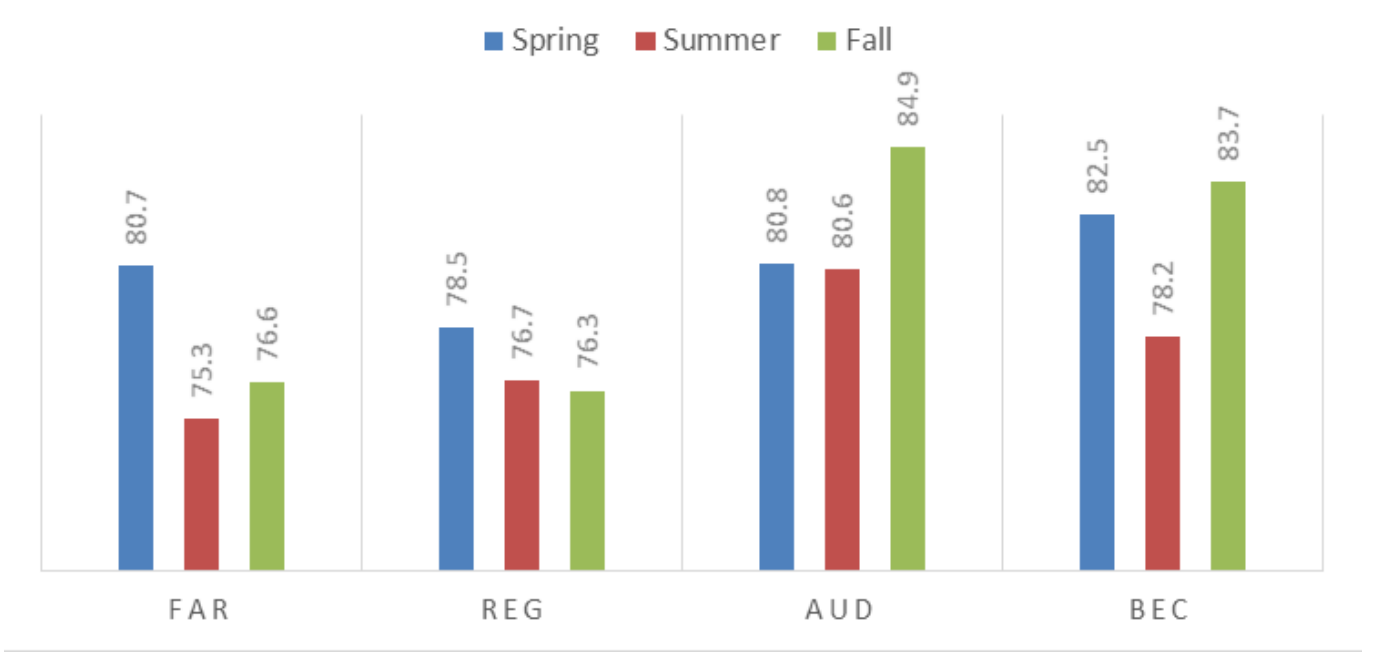


Figure 3. Average Pass Rate for Interns by Internship Semester

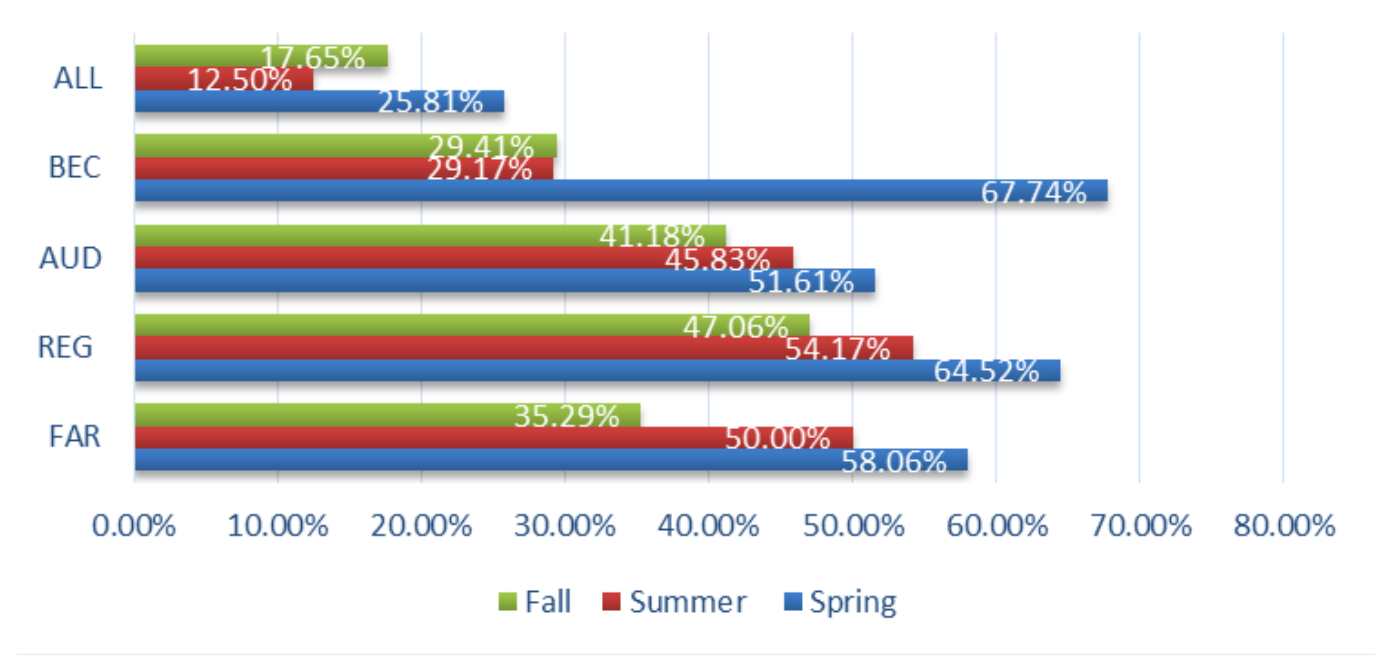

\section{Undergraduate v. Graduate Internship}

State law requires that students complete their undergraduate degree prior to sitting for the CPA exam. However, students can complete an internship in either their undergraduate or graduate program. Forty-one of the students in our sample completed their internship as an undergraduate student prior to entering the graduate program. These students gained valuable real world experience earlier in their careers than students that waited to complete an internship during their graduate program. In general, we find that students that completed internships during their undergraduate programs had higher exam scores on all sections of the exam with the exception of BEC. The exam pass rates for undergraduate students was also higher, with the FAR and REG section pass rates being significantly higher for undergraduate interns. We also find that students that complete their internships during their undergraduate program have significantly higher pass rates for the FAR and REG sections and pass more parts than those that complete internships during their graduate program. Spring undergraduate interns have significantly higher FAR grades than fall undergraduate interns. Graduate students that complete their internships during the fall semester score significantly higher on the AUD section as compared to fall and spring graduate interns. Spring graduate interns also score significantly higher on the BEC section than do summer graduate interns. In addition, spring undergraduate interns score significantly higher on the FAR section of the exam than fall and summer undergraduate interns.

On average, students with undergraduate internships passed 2.34 sections of the exam prior to graduation and graduate interns passed 1.55 sections, with this difference between the groups being statistically significant. 
Figure 4. Average CPA Exam Grade for Undergrad v. Grad Interns

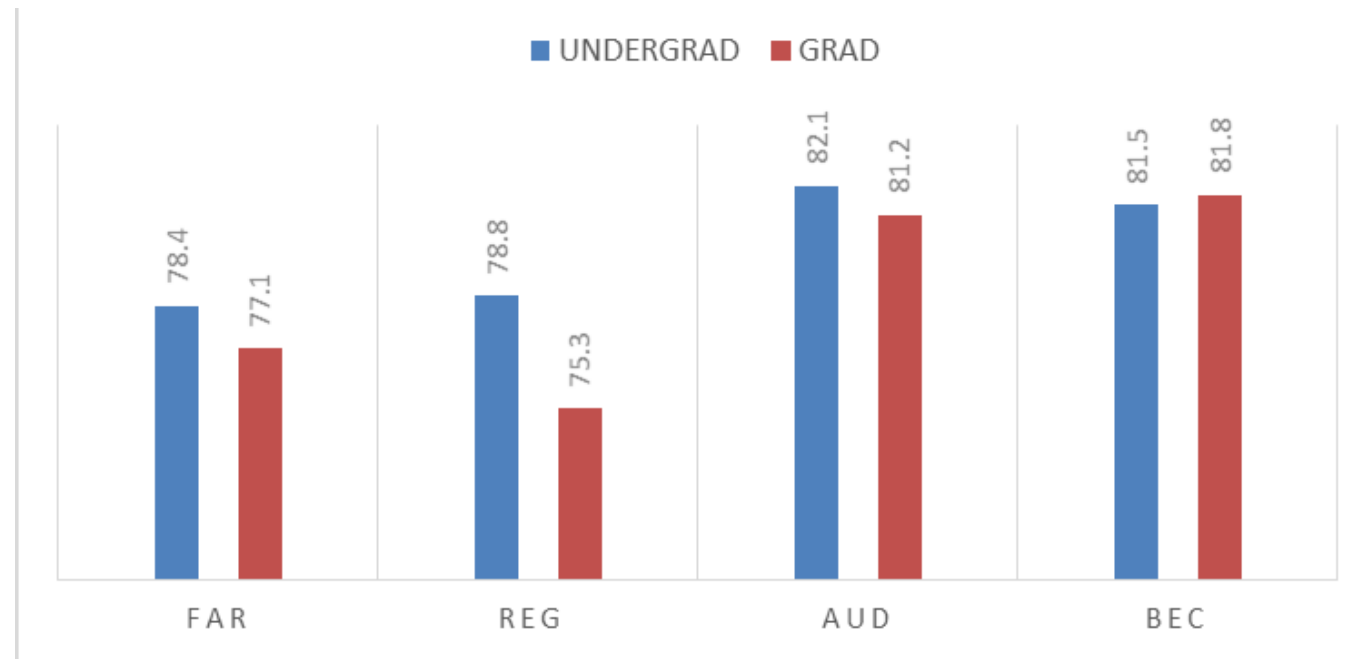

\section{Gender}

Several studies suggest that male and female students have different learning styles and preferences (Kulturel-Konak, D'Allegro \& Dickinson, 2011). Rosati (1999) finds that in general both male and female students show a preference for active learning. Active learners retain and understand information better after activities such as discussing, explaining, or applying it. However, Rosati (1999), also finds that male students were significantly more confident in trying things out rather than thinking about how to do them. Additionally, according to Wehrwein, Lujan, and DiCarlo, female students tend to prefer unimodal learning (i.e. single mode of information presentation), whereas, male students tend to prefer multiple modes of learning. This suggests that students may respond differently to the internship experience based on learning styles most often associated with their gender. Although we expect both male and female students to benefit from an internship, we may also expect to see some differences in CPA exam performance for male and female students given that some differentiation has been documented in learnings styles between genders.

On average we find that there is no significant difference between the average scores of male and female students on any part of the exam; however, males are significantly more likely to pass the REG portion of the exam than are females. The average pass rate for male students exceeds that for female students on every section of the exam with the exception of BEC, where the female pass rate is 48 percent as compared to 36 percent for males. However, the average scores for male and female students are fairly consistent. Among male and female students that have not had internships, males are more likely to pass the AUD section than are females; however, the difference between the pass rates becomes insignificant if both male and female students have completed internships. We also find significant differences in pass rates between male and female students that complete internships in the fall and summer. Specifically, we find that male students completing internships during the fall semester have significantly higher pass rates for FAR, REG, and BEC as well as pass more sections of the exam than their female counterparts. Additionally, male students that have had fall internships have significantly higher scores on the REG section of the exam as compared to female students completing internships during the fall, and male students completing summer internships are more likely to pass the REG section of the exam than their female counterparts. 
Figure 5. Average Pass Rates by Gender

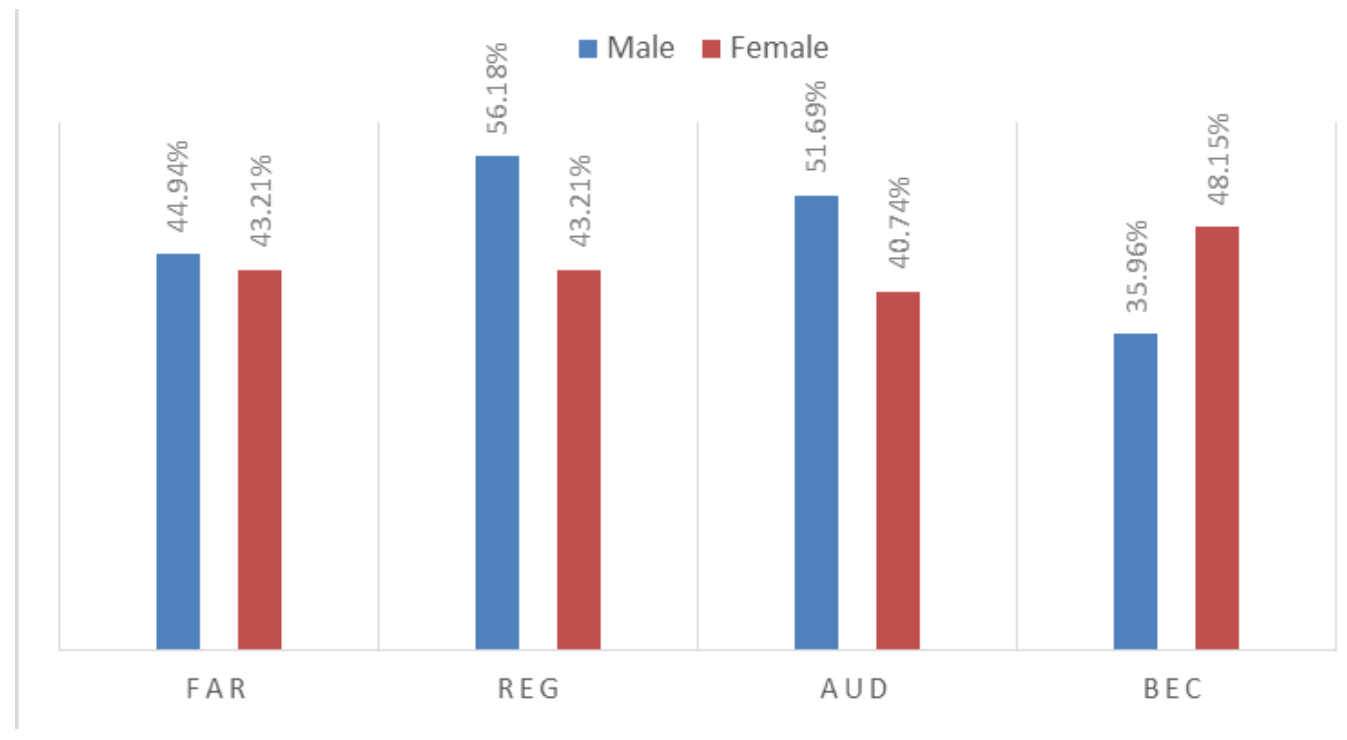

Figure 6. Gender Comparison - Average CPA Exam Score

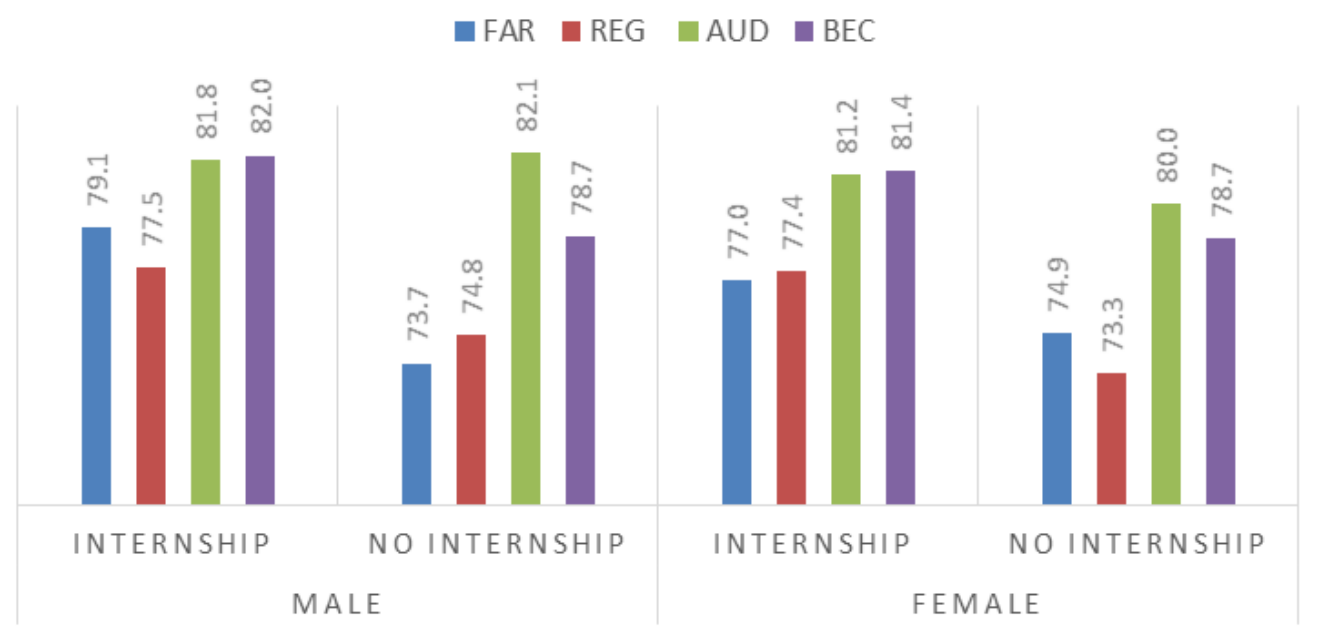

\section{Female Students}

Women that have had internships outscore those without internships consistently on every section of the CPA exam. This difference is practically significant but due to small sample sizes is not statistically significant. The pass rate and number of parts passed, on average, is higher for women that have completed internships as compared to those that have not. The averages suggest that overall women perform better on the CPA exam after having an internship. Women that complete internships during their undergraduate degree have significantly higher pass rates on the FAR section than those that complete internships during the graduate program. Female students that complete undergraduate internships have higher pass rates on every section of the exam, except BEC, as compared to female students that complete internships during their graduate program; the undergraduate interns also pass more sections of the exam as compared to graduate interns. 


\section{Male Students}

Men that have had internships outscore those without internships consistently on every section of the CPA exam, with the exception of the audit section, which is counterintuitive. We also find that male students that completed internships during the spring are significantly more likely to pass the FAR, REG, and BEC sections than those that completed internships at other times during the year. Additionally, men that complete internships during the spring have significantly higher scores on the REG section and are more likely to pass more parts of the CPA exam, than are those that complete internships at any other time during the year. Male students that complete internships during their undergraduate program also have significantly higher pass rates for REG and AUD and pass more parts of the CPA exam than those that complete internships during their graduate program.

\section{CONCLUSION}

The AICPA introduced the updated version of the CPA Exam on April 1, 2017. The revised exam places greater emphasis on candidates' cognitive skills such as analytical ability, critical thinking, and problem solving. The analysis performed by the authors suggests that there is merit in application-based learning that translates to greater success on the CPA exam. As the CPA exam becomes more geared toward first year staff accountants more universities should consider incorporating internships into their accounting programs. When internships are not an option, applicationbased learning can be accomplished through other practical experience opportunities. A class project working with a local business or nonprofit could provide application-based learning if an internship is not available.

Application-based learning not only improves CPA exam scores, it also prepares students for employment. We suggest that students be required to complete an internship or some other type of practical experience as part of their undergraduate or graduate accounting program. In order to provide this type of practical experience accounting programs must partner with CPA firms or local businesses and non-profits. Most schools have career services that help place students in full time positions. These already established contacts can help to establish internship opportunities. Our experience has been that firms like to hire interns because it provides them with the opportunity to evaluate potential full time hires. When schools partner with firms to set up internships or other practical opportunities it's a winning proposition for schools, students, and firms.

\section{AUTHOR BIBLIOGRAPHIES}

Stephanie Hairston, PhD, CPA is affiliated with Georgia Southern University. Her research interests include archival capital markets, audit risk assessment, and the market for audit services. She teaches financial accounting. E-mail: shairston@georgiasouthern.edu

Charles Harter, $\mathrm{PhD}, \mathrm{CPA}, \mathrm{CFE}$ is affiliated with Georgia Southern University. His research interests include capital markets, executive compensation, and pedagogy. He teaches financial accounting.

E-mail: charter@georgiasouthern.edu

Britton McKay, PhD, CFE is affiliated with Georgia Southern University. Her research interests include knowledge structures, decision aids, ERP systems and implementation strategies, tax practice, and practical financial education. She teaches financial accounting, tax, and accounting information systems. E-mail: bmckay@georgiasouthern.edu

\section{REFERENCES}

Association of International Certified Public Accountants (AICPA). (2017). 2017 Trends in the supply of accounting graduates and the demand for public accounting recruits. Retrieved from https://www.aicpa.org/InterestAreas/AccountingEducation/NewsAndPublications/DownloadableDocuments/2017trends-report.

Bonner, S. and P. Walker (1994). The effects of instruction and experience on the acquisition of auditing knowledge. The Accounting Review. Vol 69, p 157-178.

Bruschi, William. (1969). Issues Surrounding Qualifying Experience Requirements. Journal of Accountancy, March 1969, pp. 47-54.

Copyright by author(s); $\underline{\text { CC-BY }}$ 
Decker, Michael. (2017). The Evolution of the CPA Exam. Pennsylvania CPA Journal. Retrieved from https:/www.picpa.org/articles/picpa-news/2017/08/31/the-evolution-of-the-cpa-exam.

Kulturel-Konak, S., M.L. D'Allegro, and S. Dickinson, (2011). Review Of Gender Differences In Learning Styles: Suggestions For STEM Education. Contemporary Issues In Education Research 4(3): 9-18.

Rosati, P. (1999). Gender Differences in the Learning Preferences of Engineering Students. Conference Presentation: The University of Ontario.

Wehrwein, Erica, Heidi Lujan, and Stephen DiCarlo. (2007). Gender differences in learning style preferences among undergraduate physiology students. Advanced Physiology Education 31(2007): 153-157. 


\section{NOTES}

